\title{
The cholinergic influence on the mesenteric ganglion affects the liberation of ovarian steroids and nitric oxide in oestrus day rats: characterization of an ex vivo system
}

\author{
Adriana Vega Orozco, Zulema Sosa, Verónica Fillipa ${ }^{\mathbf{1}}$, Fabian Mohamed ${ }^{\mathbf{1}}$ and Ana María Rastrilla \\ Laboratorio de Biología de la Reproducción (LABIR), ㅅ́rea de Morfología, Facultad de Química, Bioquímica y Farmacia, Universidad Nacional de San Luis, \\ Chacabuco 917, 5700 San Luis, Argentina \\ (Requests for offprints should be addressed to A M Rastrilla; Email: amras@unsl.edu.ar)
}

\begin{abstract}
The axons that constitute the ovarian nervous plexus originate mostly in the principal neurons of the superior mesenteric ganglion (SMG) that is part of the sympathetic ganglionic chain and exhibits cholinergic receptors. In order to observe the effect of acetylcholine, the main neurotransmitter in the ganglionic transmission, the purpose of the present work was: first, to standardize an integrated ex vivo superior mesenteric ganglion-ovarian nervous plexus-ovary (SMG-ONP-O) system in oestrus day rats; secondly, to determine if the ganglionic cholinergic stimulus modifies the release of nitric oxide and steroids in the ovary compartment in the absence of humoral factors; and thirdly, to investigate if there are differences in the responses between the left and right ovaries caused by the neural stimulus. The ex vivo experimental left and right systems were developed and standardized. The systems were incubated in Krebs-Ringer phosphate buffer in a Dubnoff metabolic shaker. The progesterone release was determined to standardize the incubation times, obtaining different responses between the left and right systems, which shows that both systems have their own autonomic tone. Non-specific stimulation with $\mathrm{KCl}$ in the ganglion compartment provoked different responses in terms of release of progesterone and oestradiol. Progesterone decreased in the left and right systems.
\end{abstract}

However, oestradiol diminished at short times and increased at 60 and $120 \mathrm{~min}$ in the left ovary, whereas it increases at 30 and $60 \mathrm{~min}$ in the right ovary. These different responses show the sensitivity and viability of both systems. When acetylcholine was used in the ganglion compartment, the release of nitric oxide, progesterone, androstenedione and oestradiol was evaluated. The liberation of nitrite increased at 15, 30 and $60 \mathrm{~min}$ in the left system and decreased in the right system at $120 \mathrm{~min}$. Progesterone showed a decrease in its release at 15,30 and $120 \mathrm{~min}$ and androstenedione at $15 \mathrm{~min}$ in the left ovary compartment. In the right ovary, only progesterone decreased in relation to the control at $120 \mathrm{~min}$ while androstenedione did not show significant changes. Oestradiol showed an increase in the left ovary compartment at all the studied times, while in the right ovary it did not show any changes. These results indicate that the neural stimulus from the superior mesenteric ganglion through the ovarian nervous plexus is one of the factors modulating the secretory activity of the ovarian steroids and nitric oxide. The system is viable and also shows a different sensitivity of the left ovary in relation to the right one at least in this cycle stage, characterized by marked irrigation and profound structural changes in the ovary.

Journal of Endocrinology (2006) 191, 587-598

\section{Introduction}

Gerendai et al. (1998), using a viral tracing technique, have provided the first morphological evidence of the existence of a neuronal multi-synaptic way between the ovary and various centres of the central nervous system through the sympathetic ganglionic pathway. Experiments carried out in our laboratory have shown that coeliac ganglion stimulus with cholinergic agents and an adrenergic agent modifies the ovarian steroids release through the superior ovarian nerve (Sosa et al. 2000, 2004, Casais et al. 2001, Delgado et al. 2004). On the other hand, the intracerebroventricular injection of epinephrine modifies rapidly the concentration of progesterone in the ovarian vein of dioestrus day 1 and dioestrus day 2 rats (De Bortoli et al. 1998). This may provide physiological evidence of the participation, at least in part, of the sympathetic ganglionic pathway in the responses observed, acetylcholine being the classic preganglionic neurotransmitter.

The ovarian nervous plexus (ONP), whose fibres originate mostly in the neurons of the mesenteric ganglia, reaches the ovary and accompanies the ovarian artery in its entrance through the hilium (Baljet \& Drukker 1979, Klein \& Burden 1988a). The plexus innervates the blood vessels musculature, serving an important function in the regulation of the blood flow (Walles et al. 1978), and its veins form a net around the ovary cortex and do not have direct relationship with the 
corpora lutea and the granulosa cells (Stefenson et al. 1981, Burden et al. 1985).

In relation to the mesenteric ganglia, it constitutes a component of the sympathetic prevertebral ganglionic pathway. The superior mesenteric ganglion (SMG) has the specific structures to respond to cholinergic stimulus, such as nicotinic and muscarinic receptors in the ganglionic neurons called principal neurons (Prud'Homme et al. 1999); muscarinic receptors are also present in the interneurons, such as the small intensely fluorescent cells and peptidergic cells (Jarvi 1989). Neuropeptide Y, substance P, norephinephrine, and nitric oxide (NO) constitute the main postganglionic neurotransmitters released by the ganglion (Klein \& Burden 1988b).

The study of the indirect immunofluorescence reveals that in the mesenteric ganglion, the distribution of nitric oxide synthase (NOS), synthesis enzyme of NO, has one possible colocalization with immunoreactive neuropeptides and with two enzymes of the catecholamine synthesis pathway, tyrosine hydroxylase and dopamine $\beta$-hydroxylase, as well as the enzyme for the acetylcholine synthesis pathway, choline acetyltransferase (Lars-Gösta et al. 1997). The nitric oxide is considered as a neurotransmitter and biological mediator of the neuroendocrine axis and there is abundant evidence of its participation in reproduction control (Brann et al. 1997, Motta et al. 2001, Delgado et al. 2004). However, there is little information about the role played by the neural factors in NO release in cyclic rats. Considering the increasingly recognized influence of the ovary innervation in the control of the diverse organ functions in different reproductive states (Aguado \& Ojeda 1984, Sosa et al. 2000, 2004, Casais et al. 2001, Garraza et al. 2004), and the participation of NO in steroidogenesis, as observed in prepubertal rats (Delgado et al. 2004), and also in the biochemical and vascular changes that occur in the ovulating period, development and regression of the corpus luteum (Acosta \& Miyamoto 2004), we also thought it could be interesting to study the neural influence of the superior mesenteric ganglion on the $\mathrm{NO}$ ovarian liberation during oestrus. The oestrus is the stage of the oestrous cycle when there is more ovarian irrigation (Acosta \& Miyamoto 2004), and the nervous plexus is related with the blood flow (Lawrence \& Burden 1980). With this purpose in mind, this work intends (1) to standardize an integrated ex vivo superior mesenteric ganglion-ONP-ovary system in oestrus day rats; (2) to determine if the ganglion cholinergic stimulus modifies the release of nitric oxide and steroids in the ovary compartment in the absence of humoral factors; and (3) to investigate if there are differences in the responses between the left and right ovaries caused by the neural stimulus.

\section{Materials and Methods}

\section{Animals}

Virgin Holtzman strain adult female rats on the day of oestrus (E) weighing $250 \pm 50 \mathrm{~g}$ were used in all the experiments. The rats were kept in a light (lights on from 0700 to $1900 \mathrm{~h}$ ) and controlled-temperature room $\left(24 \pm 2{ }^{\circ} \mathrm{C}\right)$. Animals had free access to food (Cargill, SACI, Saladillo, Buenos Aires, Argentina), and tap water was available ad libitum. Vaginal smears were taken daily, and only the rats exhibiting at least two 4-day consecutive oestrous cycles were used. Groups of six animals in oestrus (E) were used for the experimental procedure. This stage was chosen for three important reasons: first, because it is the period of the oestrous cycle when there is more ovarian irrigation, and the increased values of oestrogen cause a rapid dilation of blood vessels by activating endothelial NOS (Acosta \& Miyamoto 2004); secondly, because the ONP fibres are mainly perivascular (Lawrence \& Burden 1980) and could take part in the vascularization changes that occur in this stage; and thirdly, because it is a stage of deep biochemical and structural changes (Mayerhofer \& Fritz 2002). The experiments were performed according to the procedures approved in the UFAW Handbook on the Care and Management of Laboratory Animals (Poole 1999) and the Guide for Animal Use and Handling of the National University of San Luis, Argentina.

\section{Reagents}

The following drugs: L-acetylcholine hydrochloride (Ach), ascorbic acid, bovine serum albumin fraction V (BSA), sulphanilamide and N-1-naphthyl-ethylenediamine were purchased by the Sigma Chemical Co. Other reagents and chemicals were of analytical grade. 1,2,6,7-[ $\left.{ }^{3} \mathrm{H}\right]$ Progesterone $(107 \cdot 0 \mathrm{Ci} / \mathrm{mmol}), 1,2,6,7-\left[{ }^{3} \mathrm{H}\right]$ androst $4-$ ene-3,17 dione $(115 \cdot 0 \mathrm{Ci} / \mathrm{mmol})$ and $17-\beta-2,4,6,7-\left[{ }^{3} \mathrm{H}\right]$ oestradiol $(102 \cdot 0 \mathrm{Ci} / \mathrm{mmol})$ were provided by New England Nuclear Products (Boston, MA, USA).

\section{Surgical procedure}

The procedure was carried out between 1500 and $1600 \mathrm{~h}$. taking account of previous descriptions of the anatomical trajectory of this neural pathway as a guide (Lawrence \& Burden 1980, Klein \& Burden 1988a; Fig. 1a). Rats were anaesthetized with ether under a bell, and the left and right systems were immediately removed by dissection. Each system is conformed by the ovary, the fibres that constitute the ovarian nervous plexus parallel to the ovarian artery and the superior mesenteric ganglion accompanied by some small ganglia surrounding it. The total surgical procedure was completed in 1-2 min. The strip of tissue was carefully dissected avoiding contact between the surgical instruments, the nerve fibres and the ganglion. This is essential in order to prevent spontaneous depolarizations of the nerves which might be caused by an inappropriate contact. The left and right mesenteric ganglion-ONP-ovary systems were washed with incubation solution and immediately placed in one cuvette with two compartments. The superior mesenteric ganglion was placed in a compartment and the ovary in the other one, both joined by the ONP which had to remain humid with the working solution (Fig. 1b). 


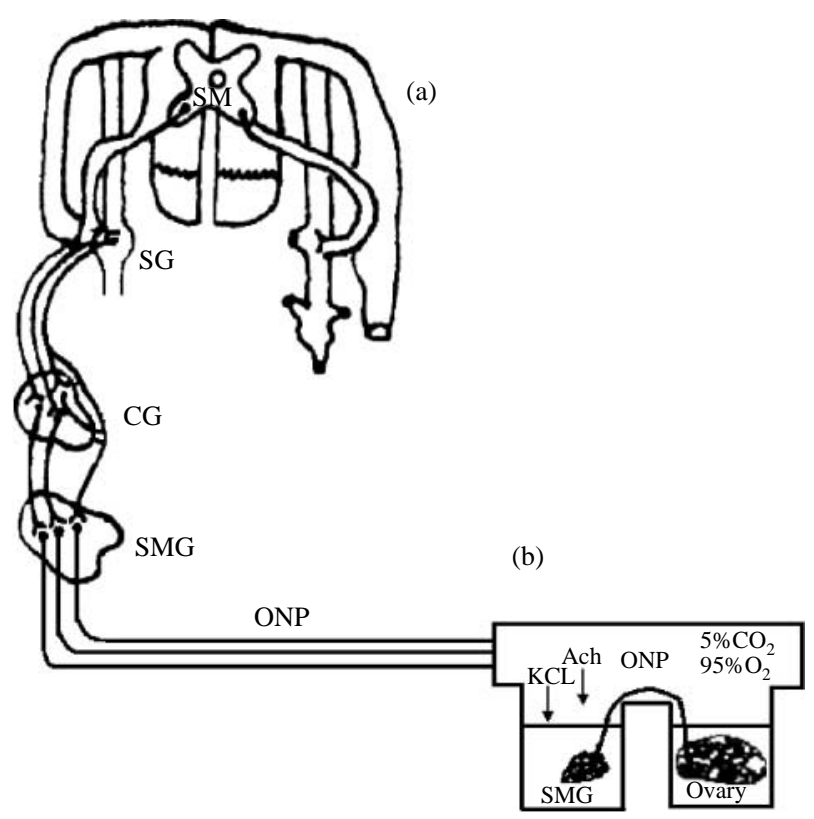

Figure 1 (a) Schematic representation of the neural connection between the superior mesenteric ganglion and the ovary joined by the ovarian nervous plexus. (b) The cuvette utilized for the subsequent incubation of the system. SM, spinal marrow; SG, sympathetic ganglion; CG, coeliac ganglion; SMG, superior mesenteric ganglion; ONP, ovarian nervous plexus; $\mathrm{KCl}$, potassium chloride; Ach, acetylcholine.

\section{Histological control of the superior mesenteric ganglion}

Immediately before and after incubation $(120 \mathrm{~min})$, the presence of the superior mesenteric ganglion was confirmed in the system by the application of routine histological techniques. The presence of the ganglion was verified in the removed system before the incubation in similar conditions to the systems that will be used later. The material was fixed with Bouin's fluid. Serial cuts of $5 \mathrm{~mm}$ thickness were carried out utilizing a sliding Reichert-Jung HN-40 microtome. Preparations were dyed with haematoxylin-eosin and coated with sintetle balsam. The micrographic image was captured using a Leitz-Dialux photomicroscope, equipped with a Leica camera. This system, using a twenty-five times objective, was used to examine tissue sections.

\section{Standardization of incubation times}

Rats on oestrus day were anaesthetized with ether under a bell for the surgery. The standardization tests were carried out measuring progesterone since it is a stage when the transformation of follicles to corpora lutea starts, and, consequently, the response to the neural stimulus in the progesterone liberation could be more sensitive. The surgery was carried out between 1500 and $1600 \mathrm{~h}$. taking advantage of the stable progesterone concentrations that occur at that time of the day. The ex vivo system was removed, cleaned with incubation medium and immediately placed in a cuvette with two compartments and incubated in Dubnoff metabolic shaker in an atmosphere of $5 \% \mathrm{CO}_{2}$ in $95 \% \mathrm{O}_{2}$ at $37{ }^{\circ} \mathrm{C}$. Each compartment contained $2 \mathrm{ml}$ Krebs-Ringer bicarbonate buffer, $\mathrm{pH} 7 \cdot 4$, with the addition of dextrose $(0 \cdot 1 \mathrm{mg} / \mathrm{ml})$ and albumin $(0.1 \mathrm{mg} / \mathrm{ml})$ in both compartments, which has been described for ovary incubation in other in vitro systems (Aguado et al. 1982, Sosa et al. 2000).

A previously standardized volume $(20 \mu \mathrm{l})$ of incubation medium was extracted from the ovarian compartment for the determination of progesterone every $1 \mathrm{~min}$ for the first $5 \mathrm{~min}$, then every $5 \mathrm{~min}$ up to and including the 60th $\mathrm{min}$, and from then on every $10 \mathrm{~min}$ up to and including the 180th $\mathrm{min}$. The preincubation time needed for its stabilization was recorded. It was observed that stabilization was achieved at $15 \mathrm{~min}$ (see Fig. 3a and b), which was then considered to be incubation time 0 . It is emphasized that during the first $15 \mathrm{~min}$ of incubation there is a great variation in the progesterone values obtained and after that time, the values fall within a similar range. After $15 \mathrm{~min}$ of the system preincubation, the KrebsRinger solution was changed in both compartments, and ascorbic acid $(0.1 \mathrm{mg} / \mathrm{ml}$ in Krebs-Ringer) was added as an antioxidant agent (Koh \& Hille 1997) in the ganglion compartment whereas the Krebs-Ringer solution was added in the ovarian compartment. The times of extraction of the ovarian liquid were established at 15, 30, 60 and $120 \mathrm{~min}$. The greatest variations in the liberation of hormones in the right and left systems were observed at these times.

Once the system was extracted and the stabilization period had passed, the substances to be tested were added in the ganglion compartment at incubation time 0 .

\section{Experimental procedure}

Rats in oestrus were used. In order to observe the viability and functionality of the system, groups with (experimental group) and without (control group) non-specific depolarizing stimulus $\mathrm{KCl} 56 \mathrm{mM}$ (Koh \& Hille 1997) in the ganglion compartment were used. The samples of liquid from the ovarian compartment $(250 \mu \mathrm{l})$ were collected at 15, 30, 60 and $120 \mathrm{~min}$, and the progesterone and oestradiol levels were measured under these conditions in the ovary compartment.

The ganglionic cholinergic effect on the release of nitric oxide, progesterone, androstenedione and oestradiol in the ovary compartment was evaluated in relation to the control group. The cholinergic agent employed was acetylcholine (Ach), which was dissolved in a working solution at $10^{-6} \mathrm{M}$ final concentration (Delgado et al. 2004, Sosa et al. 2004). The steroids were determined by RIA and the nitrites, by the Griess method. The respective corrections were made in all cases considering the volume extracted in each test period.

\section{Nitrite assay}

Levels of nitrite, a water-soluble metabolite of nitric oxide, were measured spectrophotometrically by the Griess method 
and were expressed in nmol of nitrite per milligram of ovarian tissue per $\mathrm{ml}(\mathrm{nmol} / \mathrm{mg}$ ovary per $\mathrm{ml}$ ) (Egami \& Taniguchi 1974). The samples $(50 \mu \mathrm{l})$ were immediately mixed with Griess reagent (sulphanilamide with N-1naphthyl-ethylenediamine/ $\mathrm{HCl}$ ). After $10 \mathrm{~min}$ incubation period at room temperature, it was read for absorbance at $540 \mathrm{~nm}$, and nmols of nitrite were determined using a standard curve. The assay sensitivity was $<2.5 \mathrm{nmol} / \mathrm{ml}$. The intraassay coefficients of variation for all the assays was $<10 \cdot 0 \%$.

\section{Progesterone, androstenedione and oestradiol assay}

Steroids were measured in duplicate by RIA. The antisera were kindly provided by $\operatorname{Dr} \mathrm{R}$ Deis (Laboratorio de Reproducción y Lactancia, Mendoza, Argentina). Progesterone was measured in nanogram per milligram ovary per $\mathrm{ml}$ and assay sensitivity was $<5 \mathrm{ng}$ progesterone/ml serum. The technique sensitivity was measured in serum although in our laboratory the corresponding assays were carried out in our working solution resulting in the same sensitivity; thus, progesterone concentration is expressed as nanogram per milligram ovary per $\mathrm{ml}$ of working solution. Androstenedione and oestradiol were expressed as picograms per milligram of ovarian tissue per $\mathrm{ml}$ (picogram/milligram ovary per $\mathrm{ml}$ ), all against incubation time on the left and right systems. The assay sensitivity was $<10 \mathrm{pg}$ androstenedio$\mathrm{ne} / \mathrm{ml}$ and $<2 \cdot 2 \mathrm{pg}$ oestradiol $/ \mathrm{ml}$. The inter- and intraassay coefficients of variation in all the assays were $<10 \cdot 0 \%$.

\section{Statistical analysis}

All data are presented as means \pm s.E.M. in each group of six rats. Differences between two groups were analysed with Student's $t$-test. Analysis of variance (ANOVA I) followed by the Duncan's multiple range test was used for several comparisons. A value of $P<0.05$ was considered statistically significant (Snedecor \& Cochram 1976).

\section{Results}

\section{Histological control}

The morphological study confirmed the presence of the mesenteric ganglion in the isolated ex vivo system. The ganglion was extracted from the area proximal to the coeliac ganglion and from the area proximal to the renal and aortic artery.

Figure $2 \mathrm{a}$ and $\mathrm{b}$ is a photomicrograph of the morphologic characteristics of the mesenteric ganglion, showing numerous neuronal somas (arrowheads). The ganglion is surrounded by a thin capsule of connective tissue (Fig. 2a). Figure $2 b$ higher magnification of Fig. 2a, showing the several forms of the mesenteric neuronal somas.

\section{Standardization of the incubation times}

Figure $3 \mathrm{a}$ and $\mathrm{b}$ shows the progesterone values obtained in the left and right superior mesenteric ganglion-ONP-ovary system during $180 \mathrm{~min}$ under basal conditions in the presence of
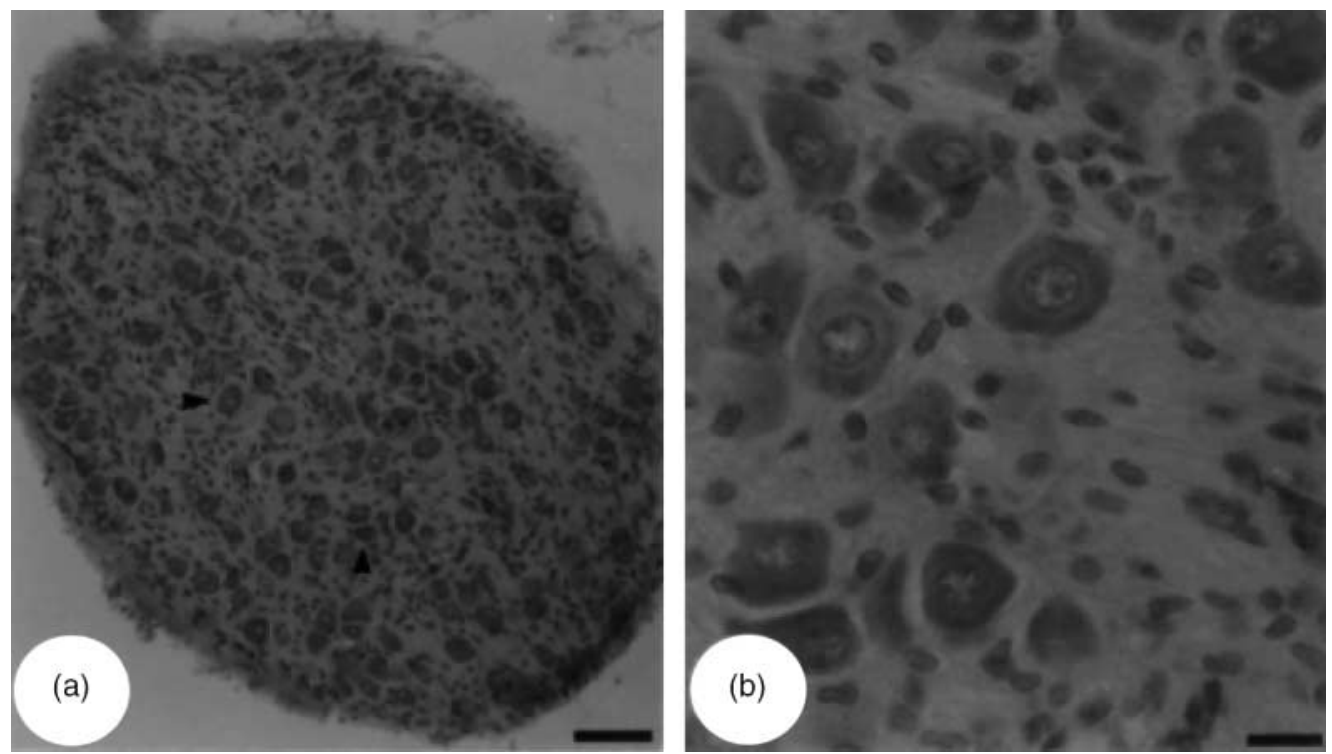

Figure 2 (a) Photomicrograph showing the morphologic characteristic of a mesenteric ganglion, with numerous neuronal somas (arrowheads). The ganglion is surrounded by a thin capsule of connective tissue, $\times 100$. Scale bar: $100 \mu \mathrm{m}$. Haematoxylin-eosin. (b) Higher magnification of (a), showing several forms of the mesenteric neuronal somas, $\times 400$. Scale bar: $25 \mu \mathrm{m}$. Haematoxylin-eosin. 
ascorbic acid in the ganglion incubation medium, demonstrating that both systems have their own neural tone when progesterone is released. In both systems, the preincubation time was at $15 \mathrm{~min}$, when stabilization was reached. It should be emphasized that before this time there is a great variation in the values obtained, and after $15 \mathrm{~min}$, considered incubation time 0 , the values fall at different times within a similar range. The variation is due likely to the cut or section of the nerve that
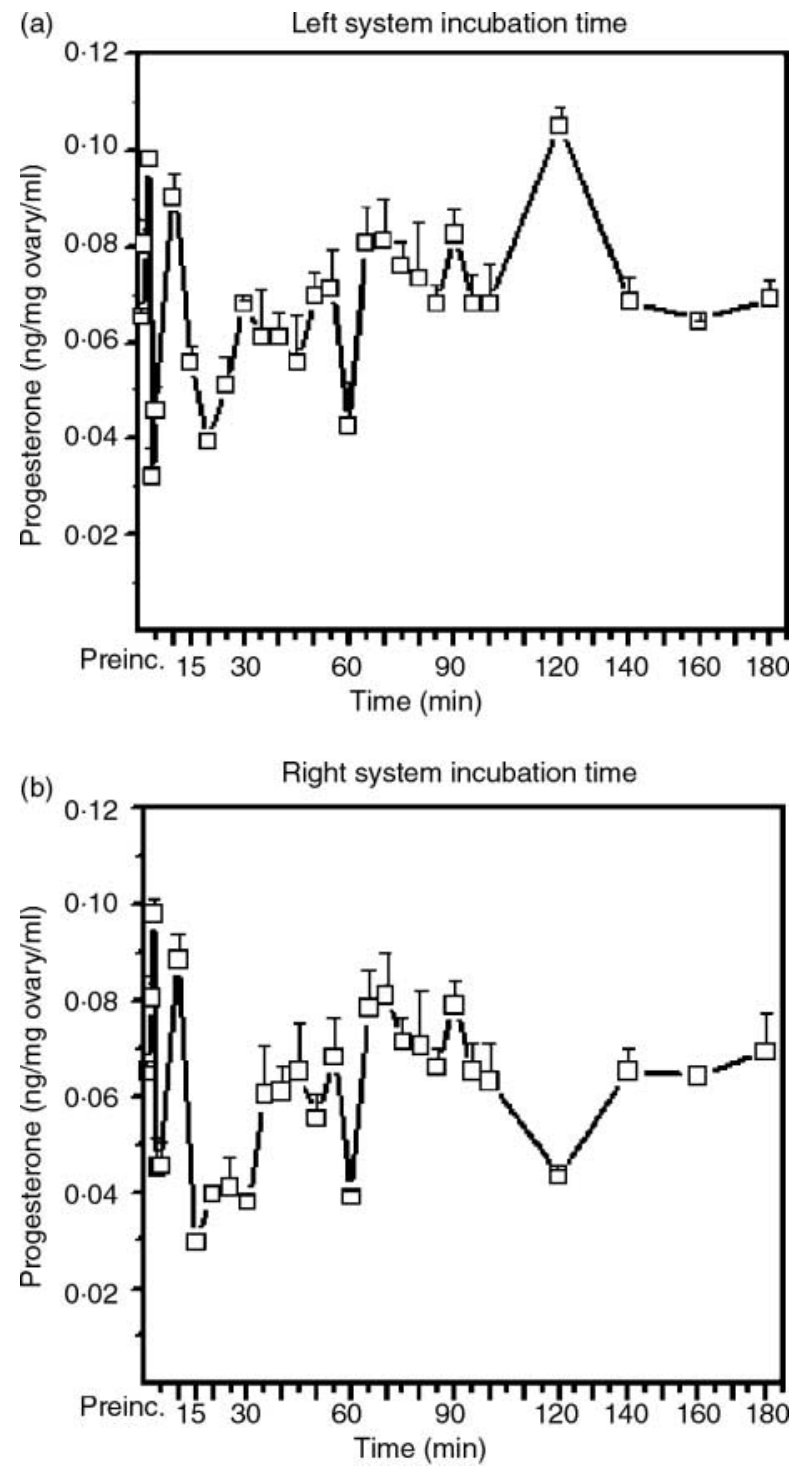

Figure 3 ( $a$ and b) Incubation times. Release of progesterone by the left (a) and right (b) ovaries in the superior mesenteric ganglionONP- ovary system obtained from the oestrus(E) day. The systems were incubated in Krebs-Ringer solution at $37{ }^{\circ} \mathrm{C}$ in an atmosphere of $95 \% \mathrm{O}_{2}-5 \% \mathrm{CO}_{2}$ for $180 \mathrm{~min}$. Progesterone concentrations were measured every $1 \mathrm{~min}$ for the first 5 min, then every 5 min up to including the 60th min, and from then on every 10 min up to and including the 180th min. Values are the means for three experiments \pm S.E.M. (Student's $t$-test). causes liberation of abundant quantities of the classic preganglionic neurotransmitter, acetylcholine.

Effect of the addition of $\mathrm{KCl} 56 \mathrm{mM}$ in the ganglion compartment on the ovarian release of progesterone and oestradiol on oestrus day

In order to determine if non-specific stimulation of the mesenteric ganglion affected the release of progesterone on the oestrus day, $\mathrm{KCl} 56 \mathrm{mM}$ was used. The $\mathrm{KCl}$ is considered to be a non-specific stimulating agent on the preganglionic nerve fibres (Koh \& Hille 1997). In this case the progesterone release observed during oestrus (E) day in the different groups was: the addition of $\mathrm{KCl}$ to the ganglion compartment in the left and right systems decreased the liberation of progesterone at all the studied times in relation to their controls. In the left system the liberation decreased at 15 and $60 \mathrm{~min}\left({ }^{\dagger} P<0 \cdot 01\right)$ and at 30 and $120 \mathrm{~min}\left({ }^{*} P<0 \cdot 001\right)$, whereas in the right system, it decreased in relation to the controls at all the studied times $\left({ }^{*} P<0 \cdot 001\right)$ (Fig. $4 \mathrm{a}$ and $\left.\mathrm{b}\right)$.

The oestradiol release measured in the left system, when $\mathrm{KCl}$ was added to the ganglion compartment decreased the liberation of oestradiol at $15 \mathrm{~min}\left({ }^{\dagger} P<0 \cdot 05\right)$, but it significantly increased at 60 and $120 \mathrm{~min}\left({ }^{*} P<0 \cdot 001\right)$ under the same conditions (Fig. 5a).

In the right system, the liberation of oestradiol increased at 30 and $60 \mathrm{~min}\left({ }^{*} \mathrm{P}<0 \cdot 001\right)$, and it reaches control value at $120 \mathrm{~min}$ (Fig. 5b).

Effect of the addition of cholinergic agents to the ganglion compartment on ovarian release of nitric oxide on oestrus day

On the day of oestrus the presence of acetylcholine as a physiological cholinergic agonist in the ganglion compartment modified the release of nitric oxide at most of the studied times, increasing in the left system in relation to the control group at 15,30 and 60 min of incubation $\left({ }^{*} P<0 \cdot 001\right)$ (Fig. 6a), while in the right system it significantly decreased at $120 \min \left({ }^{\dagger} P<0 \cdot 05\right)$ (Fig. 6b).

Effect of the addition of cholinergic agents to the ganglion compartment on ovarian steroids release on oestrus day

When the progesterone release was analysed, acetylcholine caused a significant decrease in relation to the controls at 15 , $30 \mathrm{~min}\left({ }^{\dagger} \mathrm{P}<0 \cdot 05\right)$ and $120 \mathrm{~min}\left({ }^{*} P<0 \cdot 001\right)$ of incubation in the left system (Fig. 7a).

In the right system, the decrease only occured at $120 \mathrm{~min}$ $\left({ }^{\dagger} P<0 \cdot 05\right)$ while there were no significant changes in relation to the control at the other studied times (Fig. 7b).

The presence of cholinergic agents in the ganglion compartment diminished the release of ovarian androstenedione compared with the control group at $15 \mathrm{~min}$ $\left({ }^{*} P<0 \cdot 001\right)$ in the left system. In the right system, androstenedione did not show any variations in relation to the control group (Fig. 8a and b). 

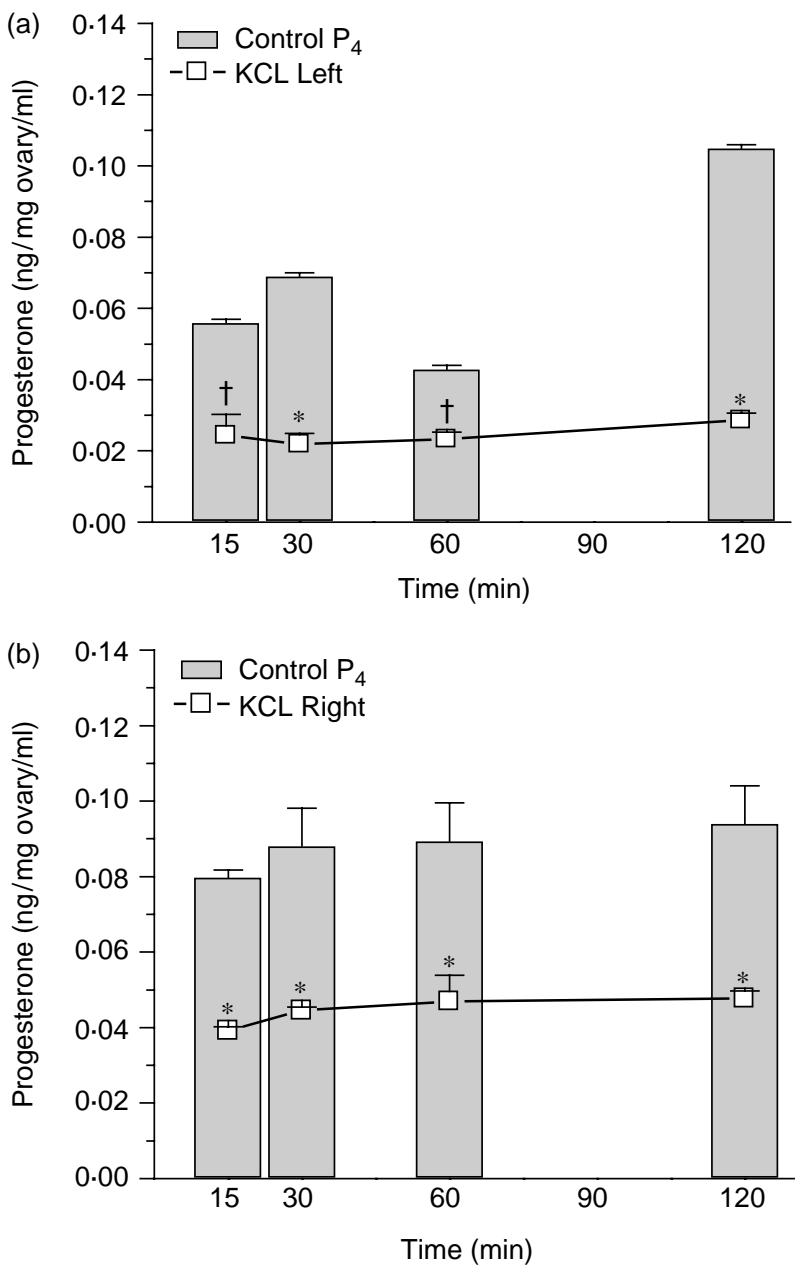

Figure 4 ( $\mathrm{a}$ and b) Effect of non-specific stimulus of $\mathrm{KCl}$ in the ganglion compartment on the left and right systems. Ovarian progesterone $\left(\mathrm{P}_{4}\right)$ release was evaluated in the ovarian compartment in the superior mesenteric ganglion-ONP-ovary system obtained from rats on oestrus day. The systems were incubated in KrebsRinger buffer, plus ascorbic acid $(0 \cdot 1 \mathrm{mg} / \mathrm{ml}$ in Krebs-Ringer) solution, at $37{ }^{\circ} \mathrm{C}$ in an atmosphere of $95 \% \mathrm{O}_{2}-5 \% \mathrm{CO}_{2}$ for 120 min without (control) and with $\mathrm{KCl} 56 \mathrm{mM}$ concentration added to the ganglionic compartment (experimental group). Values are the mean \pm S.E.M. of six animals per experimental group. Left (a) and right (b), ${ }^{*} P<0 \cdot 001$ and ${ }^{\dagger} P<0 \cdot 01$ compared with the control group. (Student's t-test, ANOVA-Duncan).

When oestradiol release was analysed, acetylcholine caused a significant increase at 15,60 and $120 \mathrm{~min}\left({ }^{*} P<0 \cdot 001\right)$ and at $30 \mathrm{~min}\left({ }^{\dagger} P<0 \cdot 01\right)$ in the left system. In the right system, oestradiol did not show any variations in relation to the control group (Fig. 9a and b).

\section{Discussion}

The ovarian nervous plexus and the vagus nerve have been involved only in the regulation of the blood flow
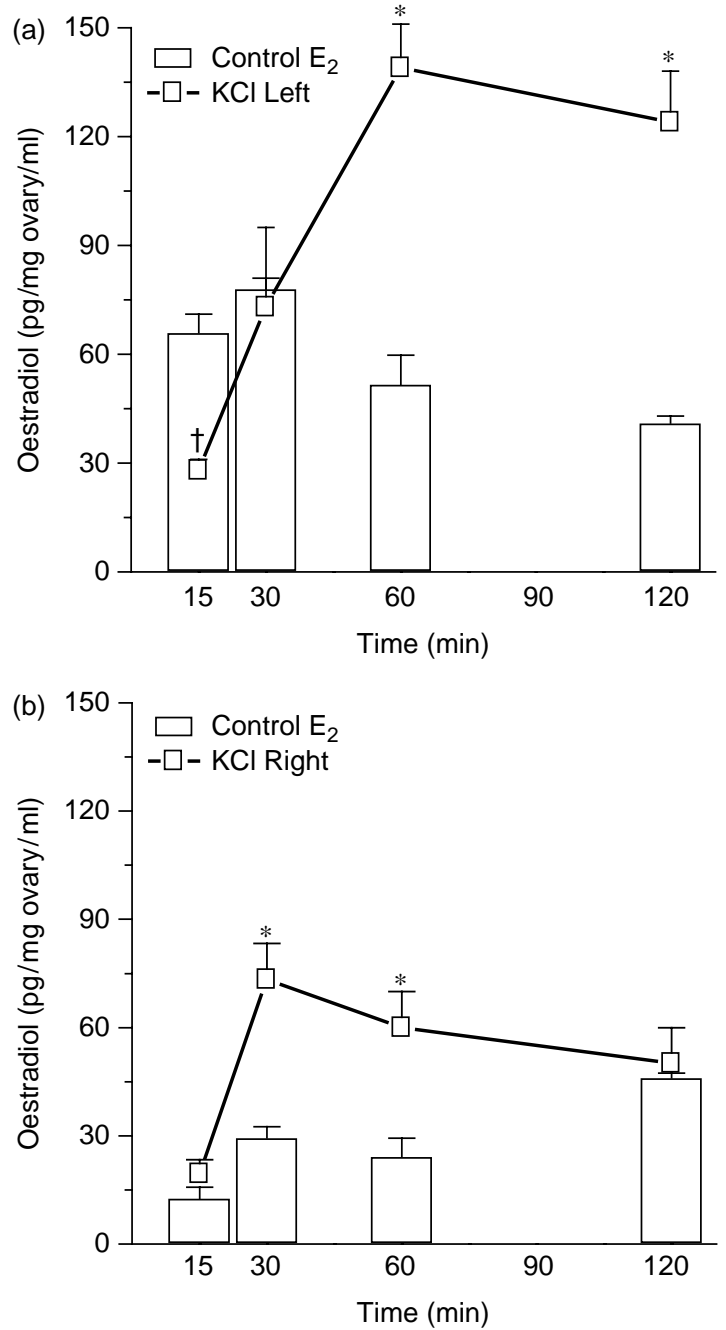

Figure 5 ( $\mathrm{a}$ and $\mathrm{b}$ ) Effect of non-specific $\mathrm{KCl}$ stimulus in ganglion compartment on the left (a) and right (b) systems. Ovarian oestradiol $\left(E_{2}\right)$ release was evaluated in this ovary compartment in the superior mesenteric ganglion-ONP-ovary system obtained from rats on oestrus ( $\mathrm{E})$ day. The system was incubated in Krebs-Ringer buffer, plus ascorbic acid $\left(0.1 \mathrm{mg} / \mathrm{ml}\right.$ in Krebs-Ringer) solution, at $37{ }^{\circ} \mathrm{C}$ in an atmosphere of $95 \% \mathrm{O}_{2}-5 \% \mathrm{CO}_{2}$ for $120 \mathrm{~min}$ without (control) and with $\mathrm{KCl} 56 \mathrm{mM}$ concentration added to the ganglion compartment (experimental group). Values are the mean \pm S.E.M. of six animals per experimental group. Left and right $* P<0.001$ and ${ }^{+} P<0 \cdot 05$ compared with the control group. (Student's $t$-test; ANOVA-Duncan).

(Burden \& Lawrence 1978, Lawrence \& Burden 1980). However, their importance in the ovarian functioning has not yet been determined. It is important to consider that this plexus not only ends around the blood vessels but also surrounds the theca cells and, in the oestrus stage, it surrounds the layer of the tecoluteinica cells (Lawrence \& Burden 1980, Vega et al. 1998).

The strict relationship of the fibres running from the superior mesenteric ganglion with the blood vessels within 

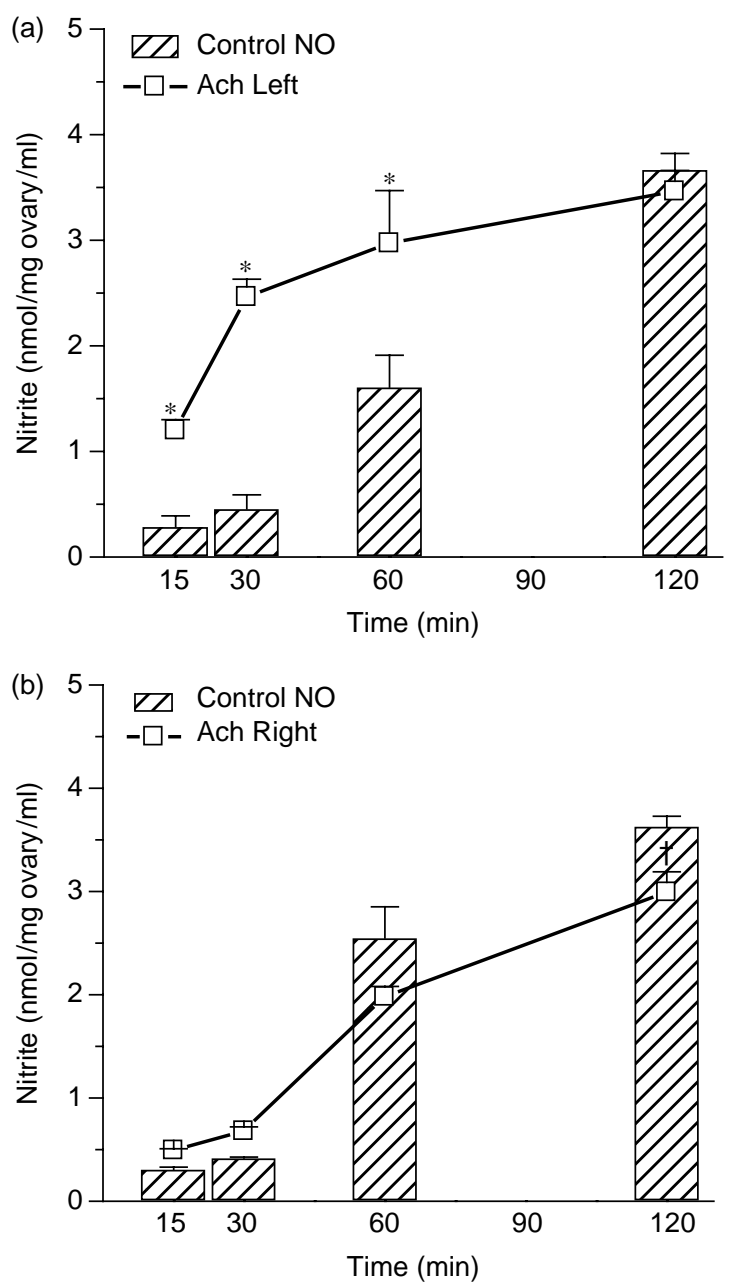

Figure 6 ( $a$ and $b$ ) NO presence in the incubation liquid of the left (a) and right (b) ovarian compartment in the superior mesenteric ganglion-ONP-ovary system of rats in oestrus, expressed as $\mathrm{nmol} / \mathrm{mg}$ ovary per $\mathrm{ml}$. Determinations were carried out under basal conditions and after the addition of acetylcholine (Ach) $10^{-6} \mathrm{M}$ in the ganglion compartment. Values are the mean \pm S.E.M., $n=6$, of two experiments. ${ }^{*} P<0 \cdot 001$. (Student's $t$-test; ANOVA-Duncan).

the ovary suggests that the nervous system might control the ovarian activity by regulating the ovarian vascular bed. Without attempting to oversimplify the complex problem of ganglionic functioning and regulation, the aim of this work was threefold: (1) to standardize an integrated superior mesenteric ganglion-ONP-ovary system in oestrus day rats; (2) to determine if the ganglionic cholinergic stimulus modifies the release of nitric oxide and steroids in the ovary compartment in the absence of humoral factors and (3) to investigate if there are differences in the responses between the left and right ovaries in this ex vivo system caused by the neural stimulus.

This system permits in vitro emulation of in vivo conditions, preserving innervation and paracrine and autocrine
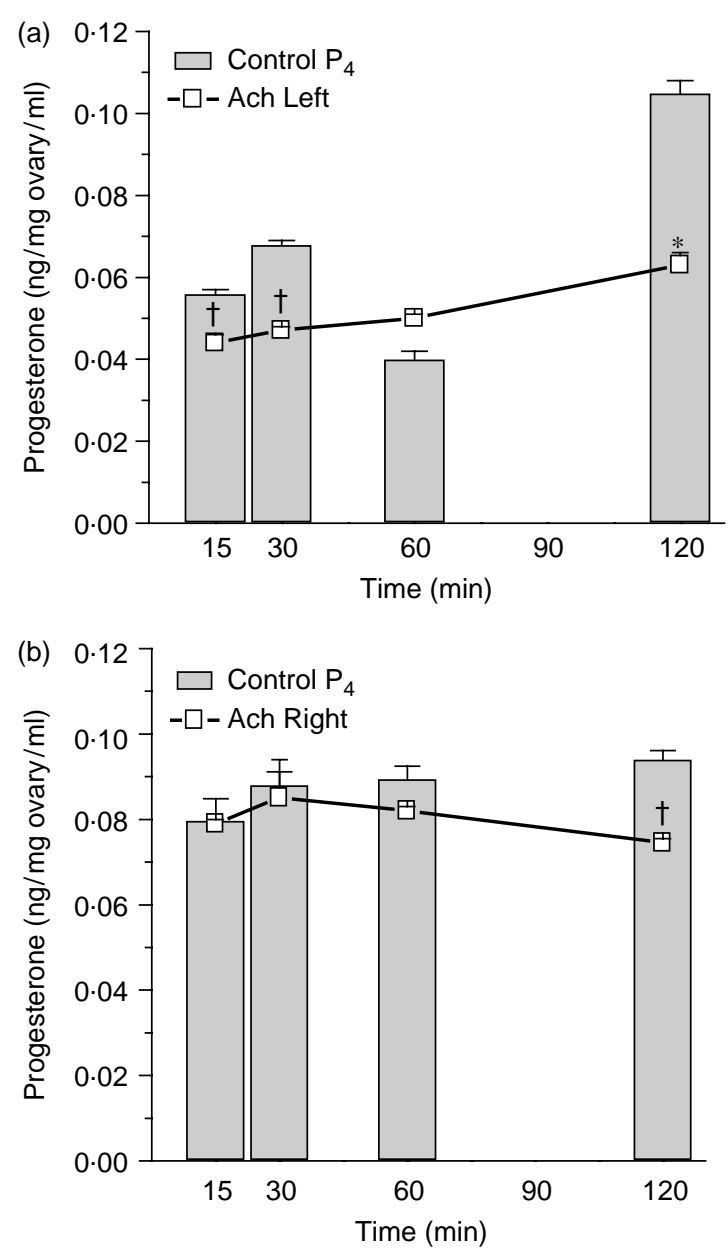

Figure 7 (a and b) Effect of cholinergic agonist in ganglion compartment on ovarian progesterone $\left(\mathrm{P}_{4}\right)$ release in the left (a) and right (b) superior mesenteric ganglion-ONP-ovary system removed from oestrus day rats. The system was incubated in KrebsRinger buffer, plus ascorbic acid $(0.1 \mathrm{mg} / \mathrm{ml}$ in Krebs-Ringer) solution, at $37{ }^{\circ} \mathrm{C}$ in an atmosphere of $95 \% \mathrm{O}_{2}-5 \% \mathrm{CO}_{2}$ for $120 \mathrm{~min}$ without (control) and with cholinergic agents in $10^{-6} \mathrm{M}$ concentration added to the ganglion compartment (experimental group). Values are the mean \pm S.E.M. of six animals per experimental group. Ach: acetylcholine; ${ }^{*} P<0 \cdot 001$ and ${ }^{\dagger} P<0 \cdot 05$ compared with the control group. (Student's $t$-test. ANOVA-Duncan).

regulation within the gland without the humoral influence. A further advantage of this system is that it possesses its own neural tone, as can be observed in the different responses of the left system in relation to the right system in the standardization of the incubation times without any ovarian or ganglionic stimulation. This is also in agreement with the results observed in another ex vivo system (Sosa et al. 2000). The levels of progesterone release in the ovarian compartment on oestrus day are different between the left and right systems showing each ovary's autonomic tone. The sensitivity of the left and right ovaries is also different. This is in agreement with the findings of other authors who have shown an 

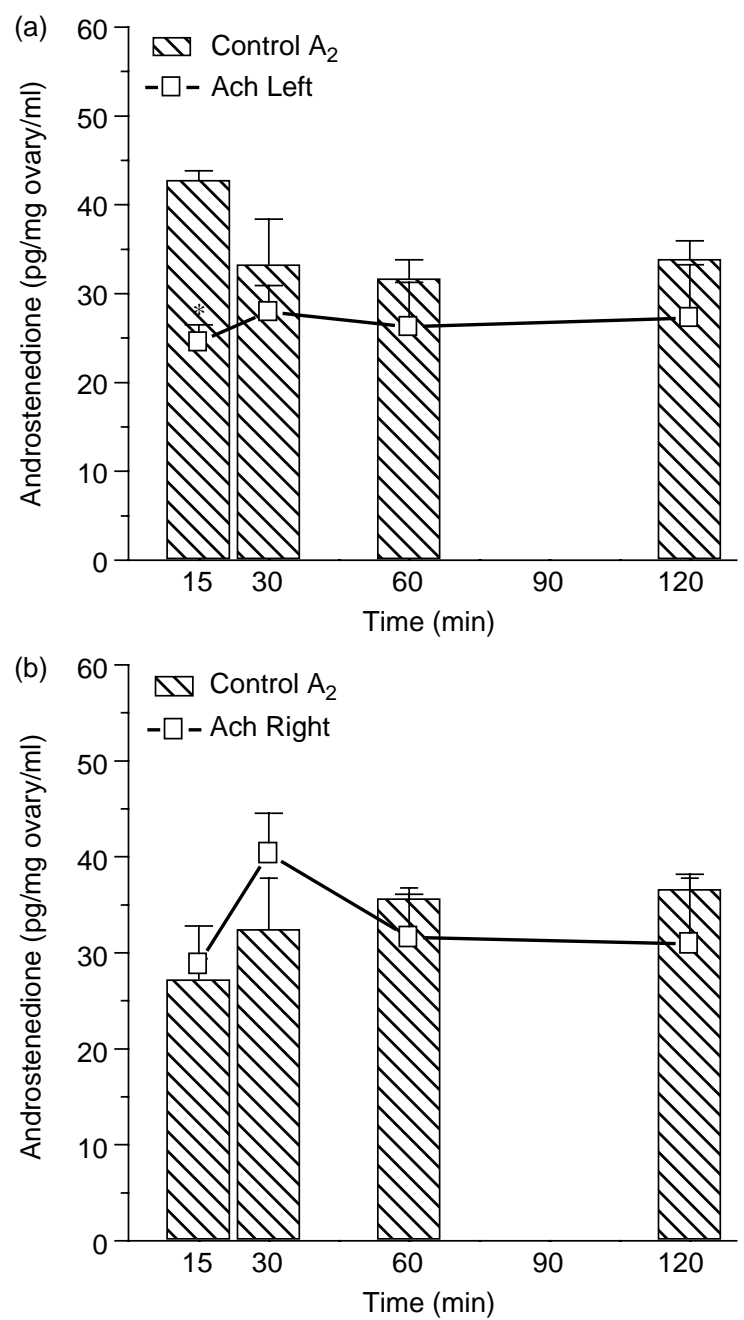

Figure 8 ( $\mathrm{a}$ and $\mathrm{b})$ Effect of cholinergic agonist in ganglion compartment on ovarian androstenedione $\left(\mathrm{A}_{2}\right)$ release in the left (a) and right (b) superior mesenteric ganglion-ONP-ovary system removed from rats on oestrus day $(\mathrm{E})$. The system was incubated in Krebs-Ringer buffer, plus ascorbic acid $(0.1 \mathrm{mg} / \mathrm{ml}$ in Krebs-Ringer) solution, at $37{ }^{\circ} \mathrm{C}$ in an atmosphere of $95 \% \mathrm{O}_{2}-5 \% \mathrm{CO}_{2}$ for $120 \mathrm{~min}$ without (control) and with acetylcholine (Ach) in $10^{-6} \mathrm{M}$ concentration added to the ganglionic compartment (experimental group). Values are the mean \pm S.E.M. of six animals per experimental group. $* P<0 \cdot 001$ compared with the control group (Student's $t$-test; ANOVA-Duncan).

asymmetry in the behaviour of the left ovary in relation to the right one according to the characteristics of the neural stimulus applied (Dominguez et al. 1989, Barco et al. 2003, Morán et al. 2005). Besides, the ganglion presence in the preparation and good conservation of its structure is kept until the end of the incubation period, which shows the excellent viability of the incubation system. This has already been observed in our previous works by using the celiac ganglionsuperior ovarian nerve (SON)-ovary system (Sosa et al. 2000, Delgado et al. 2004).
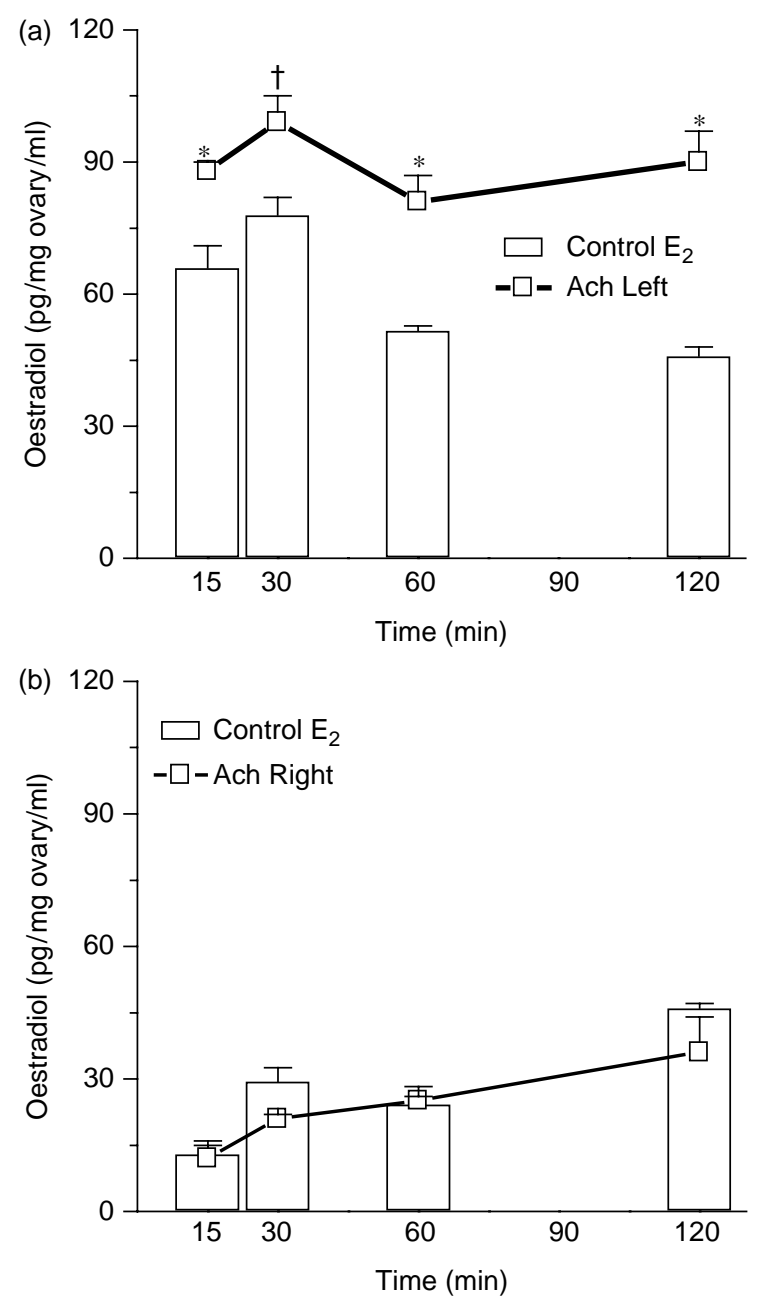

Figure 9 ( $\mathrm{a}$ and b) Effect of cholinergic agonist in ganglion compartment on ovarian oestradiol $\left(\mathrm{E}_{2}\right)$ release in the left (a) and right (b) superior mesenteric ganglion-ONP-ovary system removed from rats on oestrus day (E). The system was incubated in KrebsRinger buffer, plus ascorbic acid $(0.1 \mathrm{mg} / \mathrm{ml}$ in Krebs-Ringer) solution, at $37{ }^{\circ} \mathrm{C}$ in an atmosphere of $95 \% \mathrm{O}_{2}-5 \% \mathrm{CO}_{2}$ for 120 min without (control) and with acetylcholine (Ach) in $10^{-6} \mathrm{M}$ concentration added to the ganglionic compartment (experimental group). Values are the mean \pm s.E.M. of six animals per experimental group. ${ }^{*} P<0 \cdot 001$ and ${ }^{\dagger} P<0 \cdot 01$ compared with the control group. (Student's $t$-test; ANOVA-Duncan).

When $\mathrm{KCl}$ was added as a non-specific agent to the ganglion compartment, different responses were observed on the liberation of progesterone and oestradiol, again showing the viability of the system. The presence of $\mathrm{KCl}$ in the ganglion compartment in left and right systems causes an inhibitory effect on the liberation of progesterone at all the studied times. A different effect was observed when another $e x$ vivo coeliac ganglion-SON-ovary system was incubated with the non-specific agent in oestrus and dioestrus 1 (D1) stage in the oestrous cycle when the corpora lutea have just been formed (Sosa et al. 2000). 
In relation to oestradiol, the presence of the non-specific agent in the mesenteric ganglion caused a stimulatory effect on the liberation of the steroid in the left and the right systems but with a different secretion profile along the incubation time. The results show a difference in the physiological response and sensitivity between the left and right ovaries through time as can be observed in the basal values obtained. This would be in agreement with the studies of Morán et al. (2005), who found an apparent asymmetry in the behaviour and activity of the neural connections between the ovaries and the prevertebral coeliac-mesenteric ganglia.

On the other hand, this different reactivity of the system and the basal tone found, permit us to add different substances in the ganglion compartment such as the cholinergic agent.

The existence of an interaction between the parasympathetic and sympathetic nerves in prevertebral ganglia is well known, providing evidence of a vagal innervation of the ganglion cells in the rat (Berthoud \& Powley 1993, 1996). This vagal contact may either directly modulate the postganglionic outflow or else gate some or all the potential modulatory inputs to these postganglionic neurons, thus allowing the vagal system to exert a more selective influence on sympathetic outflow (Berthoud \& Powley 1993). These vagal projections form varicose terminal-like structures, highly suggestive of synaptic contacts surrounding individual ganglion cells, thus demonstrating the presence of cholinergic receptors in the ganglion (Berthoud \& Powley 1996). In the present experimental scheme, we used acetylcholine as cholinergic agonist because it is considered to be the classical preganglionic neurotransmitter of the sympathetic ganglionic pathway (Eccles \& Libet 1961, Berthoud \& Powley 1993). Carbacol was not used because it is a synthetic cholinergic agonist that, though more stable than acetylcholine, has activity only on a specific type of cholinergic receptors (Schroff et al. 1999), and our purpose in this work is always to emulate in an ex vivo system of the physiological conditions. Besides, the use of carbacol in other experimental schemes has shown a response with the physiological agonist higher than expected (Miller et al. 1997, Ghisdal et al. 2005). An inhibitor of the acetylcholinesterase was not used because it produces dysfunction in rats by selective complementmediated destruction of preganglionic sympathetic nerve terminals (Miller et al. 1997). The cholinergic agent in ganglion acts in different ways depending on the stage of the oestrous cycle and constitutes one of the physiological factors governing the secretory activity of the ovarian steroids and NO, as observed in another ex vivo system (Delgado et al. 2004, Sosa et al. 2004).

In recent years nitric oxide has been recognized as a paracrine molecule that evokes cell function via gas diffusion, a truly new concept in cell to cell signalling (Moncada \& Higgs 1993). NO participates in a variety of general physiological and pathophysiological processes and also acts as a luteotrophic and luteolytic factor in the corpus luteum (Fridén et al. 2000) as well as in apoptosis and steroidogenesis (Schukovsky \& Tsafriri 1994, Snyder 1996, Masuda et al. 1997). This gaseous neurotransmitter has also been involved in the regulation of the blood flow in the ovary (Thom et al. 1985).

The most relevant results concerning the action of acetylcholine on NO release was observed in the left system on oestrus day. This day is characterized by reordering and structural organization that involves follicular atresia. This atresia also involves apoptosis mechanisms serving physiologic and homeostatic functions in the development of corpora lutea (Vega et al. 1998). This is the reason why we decided to elucidate if the addition of acetylcholine to the ganglion mesenteric has an effect on the ovarian NO release in this cycle stage.

In this work, an increase in the liberation of $\mathrm{NO}$ in the ovarian compartment was observed with the addition of acetylcholine in the ganglion compartment in the left ovary up to $120 \mathrm{~min}$ whereas in the right ovary no variations were observed. This different pattern of liberation of NO is possibly due to variations in the innervation between the right and left ovaries (Dominguez et al. 1989). In other words, the ganglionic cholinergic activity provides evidence of a higher sensitivity of the left ovary to the neural stimulus, at least for the NO liberation in these oestrous cycle stages. It is important to emphasize that future studies will be carried out to determine if the nervous peripheral system through the ovarian nervous plexus, at least in oestrus, would be involved in the apoptosis of granulosa cells that lead to the process of luteogenesis in rats, as has already been observed in culture of luteal cells in human beings (Vega et al. 1998, Motta et al. 1999). In this study, it was not possible to elucidate if NO originated in ganglion by neuronal NOS (nNOS) isoenzyme stimulation under acetylcholine influence, as has already been demonstrated in other experimental schemes (Furchgott \& Zawadzki 1980), or if $\mathrm{NO}$ in ovary compartment is synthesized by isoforms, inducible NOS (iNOS) or endothelial NOS (eNOS) stimulation via the nerves. Besides, we have demonstrated that the cholinergic agent in ganglion stimulates NO liberation from the prepubertal ovary, and the $\mathrm{NO}$ is involved in the steroidogenesis in this stage via the superior ovarian nerve (Delgado et al. 2004).

In relation to the liberation of progesterone and androstenedione, the presence of the cholinergic agent in mesenteric ganglion in this experimental scheme produced an inhibition in the liberation of progesterone at 15, 30 and $120 \mathrm{~min}$ and of androstenedione at $15 \mathrm{~min}$ in the left ovary whereas in the right ovary only progesterone decreased in relation to controls at 120 min while androstenedione did not show significant changes.

The effects observed might be partly related with the liberation of NO. Indeed, there is evidence that $\mathrm{NO}$ decreases steroidogenesis although in different experimental schemes (Olson et al. 1996, Masuda et al. 1997, Vega et al. 2000). The mechanisms involved may be related to the inhibition produced by the NO of the activity of steroid synthesislimiting enzyme, cytochrome $\mathrm{P}_{450}$, of the two isoforms of adenylyl cyclase, the second intracellular messenger (McVey et al. 1999), and/or of the inhibition of the steroidogenic 
acute regulatory protein (StAR) protein (Devoto et al. 2001). In our case it should be emphasized that the terminals of the ovarian nervous plexus reach the steroidogenic cells where the inducible NOS or eNOS isoenzymes have been found (Dunnam et al. 1999). On the other hand, the effect observed might also be due to the presence of other neurotransmitters such as the substance $\mathrm{P}$ described in this nervous pathway, which may be liberated by the action of the cholinergic agent on the mesenteric ganglion. In previous studies, it has been observed that the presence of $\mathrm{P}$ substance, one of the neuropeptides described as a neurotransmitter in this neural pathway and with a sensitive function in the ovary, exhibits an inhibitory effect on the liberation of progesterone during dioestrus 1 (D1) when incubating ovaries in vitro with such neurotransmitter (Garraza et al. 2004). In addition, our work group has demonstrated that the cholinergic agent in coeliac ganglion inhibits the liberation of progesterone in D1 by decreasing noradrenaline liberation in the sympathetic terminal at ovarian level (Sosa et al. 2004).

In relation to androstenedione, it only exhibits an inhibition of its release for very short times in the left system, an effect that has also been observed in the liberation of testosterone when the inferior spermatic ganglion is stimulated by acetylcholine in a similar ex vivo system (Zhu et al. 2002). These results are in agreement with the findings reported by other researchers who have found that NO inhibits the ovarian release of androstenedione, although in different experimental schemes (Olson et al. 1996, Dunnam et al. 1999). In other words, numerous factors at the ovarian and neural levels may be interacting in the inhibition of the liberation of progesterone and androstenedione in oestrus in order to modulate the physiological processes occurring in the ovary, and may be leading to the inhibition of the steroids liberation in this oestrous cycle stage.

In relation to oestradiol, the ganglionic cholinergic action caused a significant increase at all the studied times in the left system whereas no changes were observed in the right system. The same stimulatory effect on the liberation of oestradiol was observed by other authors, who have proposed that the oestradiol increase would favour the angiogenesis, the local vasodilatation and the increase of the blood flow, facts which favour the follicular and corpus luteum development by eONS stimulation (Masuda et al. 2001, Acosta \& Miyamoto 2004). Thus, D'Albora et al. (2002) have stated that the changes in the irrigation can be caused by the NO, which, acting in a paracrine way, causes a vasodilatation and partly mediates in the blood flow increase occurring during the follicular development, the preovulatory period and the corpus luteum formation. However, other authors have suggested that the in vitro synthesis of oestradiol was inversely regulated by NO (Olson et al. 1996). Snyder et al. (1996) have stated that an increase in the production of nitric oxide inhibits the production of oestradiol in in vitro human granulosa-luteal cells cultures, being the NO capable of directly inhibiting the activity of the aromatase enzyme or indirectly decreasing the levels of the mRNA of the enzyme.
These results are likely to be due to differences in the experimental schemes used or to the lack of neural influence on those schemes. We suggest that in oestrus the innervation, in this case from the mesenteric ganglion via the ovarian nervous plexus, would participate favouring the angiogenesis and the formation and irrigation of the corpus luteum, with an increase in the production of oestradiol and NO. The luteotrophic effect of oestradiol and NO has already been observed by other authors in the oestrous cycle (Vega et al. 1998, Fridén et al. 2000, Acosta \& Miyamoto 2004).

Another neurotransmitter probably involved in the described processes is the acetylcholine liberated to the ovarian incubation liquid by ganglion stimulus. It has been suggested that acetylcholine may play a role in the cellular proliferation (Gutkind et al. 1991) and in the changes of the constantly remodelling ovarian tissue histoarchitecture (Lauder \& Schambra 1999, Mayerhofer \& Fritz 2002), both of which occur in this oestrous stage. It has also been described that cholinergic agents modify the secretion of hormones from human granulosa cells in culture (Bodis et al. 1993).

Although Burden \& Lawrence (1978) found typical sympathetic nervous fibres reaching the ovary and showing acetylcholinesterase activity, acetylcholine was not found at ovarian level. However, the presence of acetylcholine receptors in the ovary, such as the M1 and M5 muscarinic receptors, has been demonstrated (Batra et al. 1993, Arellano et al. 1999, Mayerhofer et al. 2003). Luck (1990) reported the stimulation in the production of steroids in bovine granulosa cells by cholinergic effect in ovary whereas Morley et al. (1992) did not find any increase in the progesterone production in chicken granulosa cells. Mayerhofer et al. (1992) did not find modifications in the liberation of progesterone in human granulosa cells culture by acetylcholine effect. On the contrary, Bodis et al. (1993) have stated that the cholinergic neurotransmission may have a physiological significance in the intraovarian regulatory pathways.

Although having controversial results, all these studies have suggested that the receptor of acetylcholine exists in ovarian cells and that this neurotransmitter might be involved in the complex regulation of the ovarian function in the production of steroids. These facts open the way to investigate if this pathway, the ovarian nervous plexus, participates in the liberation of acetylcholine since it is the entrance of the vagal pathway reaching the ovary, and it has been shown to have influence on the ovarian functioning. Thus, Chavez et al. (1989) by cutting the vagus nerve found a different response of the left ovary in relation to the right one, indicating that the vagal system is partly responsible for the physiological mechanisms taking place in the ovary.

In our case, the ganglion cholinergic stimulus provides evidence of a greater sensitivity of the left ovary to the neural stimulus in relation to the right ovary in every case in oestrus stage, and of an apparent asymmetry in their responses when there is a marked irrigation and profound structural changes. It cannot be elucidated if the results obtained in this study might be caused by the existence of communication between 
both ovaries, which would be via multiple pathways (Dominguez et al. 1989, Morales et al. 1993), or by the existence of some kind of blood-borne information between the ovaries, as was previously proposed (Morales et al. 1998). The results obtained might also be due to an apparent asymmetry in the activity of neural connections between the ovaries and the prevertebral sympathetic chain in addition to the fact that the number of active neurons of these connections varies during the oestrous cycle (Morán et al. 2005). We are able to state that the innervation by cholinergic stimulus of the superior mesenteric ganglion participates in the control of the corpus luteum development in a stimulatory and asymmetrical manner. This might indicate that the ovarian nervous plexus, besides regulating the blood flow, contributes to the control of the ovarian physiology with the other neural pathway entering the ovarion, the superior ovarian nerve.

\section{Acknowledgements}

This paper is dedicated to the memory of Luis Aguada $\mathrm{PhD}$ (1946-2003). This research was supported by Grant 9302 from Universidad Nacional de San Luis, Argentina. We thank to Dr R P Deis who provided the progesterone antiserum. We also acknowledge Luis Villegas for his technical assistance. This work is part of the Beca de Iniciación granted to the biochemist a Vega by Secretaria de Ciencia y Técnica, Universidad Nacional de San Luis. The authors declare that there is no conflict of interest that would prejudice the impartiality of this scientific work.

\section{References}

Acosta TJ \& Miyamoto A 2004 Vascular control of ovarian function: ovulation, corpus luteum formation and regression. Animal Reproduction Science 82-83 127-140.

Aguado LI \& Ojeda SR 1984 Prepubertal ovarian function is finely regulated by direct adrenergic influences: role of noradrenergic innervation. Endocrinology 114 1845-1853.

Aguado LI, Petrovic SL \& Ojeda SR 1982 Ovarian adrenergic receptors during the onset of puberty: characterization, distribution and coupling to steroidogenic responses. Endocrinology 110 1124-1132.

Arellano RO, Garay E \& Miledi R 1999 Muscarinic receptor heterogeneity in follicle-enclosed Xenopus oocytes. Journal of Physiology 521 409-419.

Baljet B \& Drukker J 1979 The extrinsic innervation of the abdominal organs in the female rat. Acta Anatomica 104 243-267.

Barco AL, Flores A, Chavira R, Damian-Matsumura P, Dominguez R \& Cruz ME 2003 Asymmetric effects of acute hemiovariectomy on steroid hormone secretion by the in situ ovary. Endocrine $21209-215$.

Batra S, Popper LD \& Iosif CS 1993 Characterisation of muscarinic cholinergic receptors in human ovaries, ovarian tumours and tumour cell lines. European Journal of Cancer 29 1302-1306.

Berthoud HR \& Powley TL 1993 Characterization of vagal innervation to the rat celiac, suprarenal and mesenteric ganglia. Journal of the Autonomic Nervous System 42 153-169.

Berthoud HR \& Powley TL 1996 Interaction between parasympathetic and sympathetic nerves in prevertebral ganglia: morphological evidence for vagal efferent innervation of ganglion cells in the rat. Microscopy Research and Technique 35 80-86.
Bodis J, Tinneberg HR, Papenfuss F, Torok A, Cledon P, Hanf V \& Schwarz H 1993 Cholinergic stimulation of progesterone and estradiol secretion by human granulosa cells cultured in serum-free medium. Gynecological Endocrinology 7 83-87.

Brann DW, Bhat GK, Lamar CA \& Mahesh VB 1997 Gaseous transmitters and neuroendocrine regulation. Neuroendocrinology 65 385-395.

Burden HW \& Lawrence IE Jr 1978 Experimental studies on the acetylcholinesterase positive nerves in the ovary of the rat. Anatomical Record $190233-242$.

Burden HW, Lawrence IE Jr \& Louis TM 1985 The adrenergic innervation of the guinea pig ovary during prenatal and postnatal periods. Acta Anatomica $122193-196$.

Casais M, Sosa ZY, Rastrilla AM \& Aguado L 2001 Coeliac ganglion adrenergic activity modifies ovarian progesterone during pregnancy: its inter-relationship with LH. Journal of Endocrinology 170 575-584.

Chavez R, Sanchez S, Ulloa-Aguirre A \& Domínguez R 1989 Effects on oestrous cyclicity and ovulation of unilateral section of the vagus nerve performed on different days of the oestrous cycle in the rat. Journal of Endocrinology 123 441-444.

D'Albora H, Anesetti G, Lombide P, Dees WL \& Ojeda SR 2002 Intrinsic neurons in the mammalian ovary. Microscopy Research and Technique $\mathbf{5 9}$ 484-489.

De Bortoli MA, Garraza MH \& Aguado LI 1998 Adrenergic intracerebroventricular stimulation affects progesterone concentration in the ovarian vein of the rat: participation of the superior ovarian nerve. Journal of Endocrinology 159 61-68.

Delgado SM, Sosa Z, Dominguez NS, Casais M \& Aguado L 2004 Effect of the relation between neural cholinergic action and nitric oxide on ovarian steroidogenesis in prepubertal rats. Journal of Steroid Biochemistry and Molecular Biology 91 139-145.

Devoto L, Kohen P, Gonzalez RR, Castro O, Retamales I, Vega M, Carballo P, Christenson LK \& Straus JF, III. 2001 Expression of steroidogenic acute regulatory protein in the human corpus luteum throughout the luteal phase. Journal of Clinical Endocrinology and Metabolism 86 5633-5639.

Dominguez R, Cruz ME \& Chavez R 1989 Differences in the ovulatory ability between the right and left ovary related to ovarian innervation. In Growth Factors and the Ovary, pp 321-325. Ed. AM Hirsfield (New York: Plenum Press).

Dunnam RC, Hill MJ, Lawson DM \& Dunbar JC 1999 Ovarian hormone secretory response to gonadotropins and nitric oxide following chronic oxide deficiency in the rat. Biology of Reproduction 60 959-963.

Eccles RM \& Libet B 1961 Origin and blockade of the synaptic responses of curarized sympathetic ganglia. Journal of Physiology 157 484-563.

Egami F \& Taniguchi S 1974 Nitrate. In Methods of Enzymatic Analysis, edn 2 , pp 2260-2265. Ed. HU Bergmeyr. New York: Academic Press.

Fridén B, Runesson E, Hahlin M \& Brannstrom M 2000 Evidence for nitric oxide acting as a luteolytic factor in the human corpus luteum. Molecular Human Reproduction 6 397-405.

Furchgott RF \& Zawadzki JV 1980 The obligatory role of endothelial cells in the relaxation of arterial smooth muscle by acetylcholine. Nature $\mathbf{2 8 8}$ 373-376.

Garraza MH, Aguado LI \& De Bortoli MA 2004 In vitro effect of neuropeptides on ovary or Celiac Ganglion affects the release of progesterone from ovaries in the rat. Medical Science Monitor 10 440-446.

Gerendai I, Toth IE, Boldogkoi Z, Medveczky I \& Halasz B 1998 Neuronal labeling in the rat brain and spinal cord from the ovary using viral transneuronal tracing technique. Neuroendocrinology 68 244-256.

Ghisdal P, Vandenberg G, Hamaide MC, Wibo M \& Morel N 2005 The diacylglycerol lipase inhibitor RHC-80267 potentiates the relaxation of acetylcholine in rat mesenteric artery by anticholinesterase action. European Journal of Pharmacology 517 97-102.

Gutkind JS, Novotny EA, Brann MR \& Robbins KC 1991 Muscarinic acetylcholine receptor subtypes as agonist-dependent oncogenes. PNAS $\mathbf{8 8}$ 4703-4707.

Jarvi R 1989 Localization of bombesin, neuropeptide Y, enkephalin, and tyrosine hydroxylase-like inmunoreactivities in rats coeliac-superior mesenteric ganglion. Histochemistry 92 231-236. 
Klein CM \& Burden HW 1988a Anatomical localization of afferent and postganglionic sympathetic neurons innervating the rat ovary. Neuroscience Letters 85 217-222.

Klein CM \& Burden HW $1988 b$ Substance P and vasoactive intestinal polypeptide (VIP) inmunoreactive nerve fibers in relation to ovarian postganglionic perikarya in para- and prevertebral ganglia: evidence from combined retrograde tracing and immunocytochemistry. Cell and Tissue Research 252 403-410.

Koh DS \& Hille B 1997 Modulation by neurotransmitters of catecholamine secretion from sympathetic ganglion neurons detected by amperometry. PNAS 94 1506-1511.

Lars-Gösta E, Holmberg K, Emson P, Schemmann M \& Hokfelt T 1997 Nitric oxide synthase, choline acetyltransferase, catecholamine enzymes and neuropeptides and their colocalization in the anterior pelvic ganglion and hypogastric nerve of the male guinea pig. Anatomical Record 35 68-76.

Lauder JM \& Schambra UB 1999 Morphogenetic roles of acethylcholine. Environmental Health Perspectives 107 65-69.

Lawrence IE Jr \& Burden HW 1980 The origin of the extrinsic adrenergic innervation to the ovary. Anatomical Record 196 51-59.

Luck MR 1990 Cholinegic stimulation, through muscarinic receptors, of oxytocin and progesterone secretion from bovine granulosa cells undergoing spontaneous luteinization in serum-free culture. Endocrinology 126 1256-1263.

Masuda M, Kubota T, Kamada S \& Aso T 1997 Nitric oxide inhibits steroidogenesis in cultured porcine granulosa cells. Molecular Human Reproduction 3 285-292.

Masuda M, Kubota T \& Aso T 2001 Effects of nitric oxide on steroidogenesis in porcine granulosa cells during different stages of follicular development. European Journal of Endocrinology 144 303-308.

Mayerhofer A \& Fritz S 2002 Ovarian acetylcholine and muscarinic receptors: hints of a novel intrinsic ovarian regulatory system. Microscopy Research and Technique 59 503-508.

Mayerhofer A, Föhr KJ, Sterzik K \& Gratzl M 1992 Carbachol increases intracellular free calcium concentrations in human granulosa-lutein cells. Journal of Endocrinology 135 153-159.

Mayerhofer A, Dimitrijevic N \& Kunz L 2003 The expression and biological role of the non-neuronal cholinergic system in the ovary. Life Sciences $\mathbf{7 2}$ 2039-2045.

Mcvey M, Hill J, Howlwtt A \& Klein C 1999 Adenylyl cyclase, a coincidence detector for nitric oxide. Journal of Biological Chemistry 274 18887-18892.

Miller SM, Ermilov LG, Szurszewski J, Hammond PI \& Brimijoin S 1997 Selectve disruption of neurotransmission by acetylcholinesterase antibodies in sympathetic ganglia in vitro examined with intracellular microelectrodes. Journal of the Autonomic Nervous System 67 156-167.

Moncada S \& Higgs A 1993 The L-arginine-nitric oxide pathway. New England Journal of Medicine 329 2002-2012.

Morales L, Chávez R \& Domínguez R 1993 Participation of the superior ovarian nerve in the regulation of ovulation in the prepubertal rat: differential effects of unilateral and bilateral section of the nerve. Medical Science Research 21 15-17.

Morales L, Chávez R, Ayala ME \& Domínguez R 1998 Effects of the unilateral or bilateral superior ovarian nerve section in prepuberal rats on the ovulatory response to gonadotrophin administration. Journal of Endocrinology 166 205-211.

Morán C, Franco A, Morán J, Nadal A, Morales L \& Domínguez R 2005 Neural activity between ovaries and the prevertebral celiac-superior mesenteric ganglia varies during the estrous cycle of the rat. Endocrine 26 147-152.

Morley P, Tsang BK, Whitfield JF \& Schwartz JL 1992 The effect of muscarinic cholinergic agonists on intracellular calcium and progesterone production by chicken granulosa cells. Endocrinology 130 663-670.

Motta AB, Estevez A \& de Gimeno MAF 1999 The involvement of nitric oxide in corpus luteum regression in the rat: feedback mechanism between prostaglandin F2 alpha and nitric oxide. Molecular Human Reproduction 5 1011-1016.
Motta AB, Estevez A, Tognetti T, Gimeno MAF \& Franchi AM 2001 Dual effects of nitric oxide in fuctional and regressing rat corpus luteum. Molecular Human Reproduction 7 43-47.

Olson LM, Jones-Burton CM \& Jablonka-Shariff A 1996 Nitric oxide decreases estradiol synthesis of rat luteinized ovarian cells: possible role for nitric oxide in functional luteal regression. Endocrinology 137 3531-3539.

Poole T 1999 UFAW hand book of the care and management of Laboratory animals, Vol 1 - Terrestrial vertebrates: Blackwell Publishing.

Prud'Homme MJ, Houdeau E, Serghini R, Tillet Y, Schemann M \& Rousseau JP 1999 Small intensely fluorescent cells of the rat paracervical ganglion synthesize adrenaline, receive afferent innervation from postganglionic cholinergic neurones, and contain muscarinic receptors. Brain Research 821 141-149.

Schroff K, Aschhoffa S, Schulzea J, Nägelea U \& Remiena J 1999 A new method for recoding surface compound potentials in sympathetic ganglia from mouse, rat, and guinea pig-application to muscarinic and nicotinic despolarizations. Journal of Pharmacological and Toxicological Methods $\mathbf{4 1}$ 189-194.

Schukovsky L \& Tsafriri T 1994 The Involvement of nitric oxide in the ovulatory process in the rat. Endocrinology 135 2287-2290.

Snedecor WG \& Cochram WG 1976 Statistical Methods. Ames, Iowa: The Iowa State University Press.

Snyder SH 1996 Endothelial NO. Nature 377 196-204.

Snyder GD, Holmes RW, Bates JN \& Van Voorhis BJ 1996 Nitric oxide inhibits aromatase activity: mechanisms of action. Journal of Steroid Biochemistry and Molecular Biology 58 63-69.

Sosa ZY, Casais M, Rastrilla AM \& Aguado L 2000 Adrenergic influences on coeliac ganglion affect the release of progesterone from cycling ovaries: characterisation of an in vitro system. Journal of Endocrinology 166 307-314.

Sosa Z, Delgado SM, Casais M, Aguado L \& Rastrilla AM 2004 Release of ovarian progesterone during the rat oestrous cycle by ganglionic cholinergic influence. The role of norepinephrine. Journal of Steroid Biochemistry and Molecular Biology 91 179-184.

Stefenson A, Owman C, Sjoberg NO, Sporrong B \& Walles B 1981 Comparative study of the autonomic innervation of the mammalian ovary, with particular regard to the follicular system. Cell and Tissue Research 215 47-62.

Thom SA, Hughes AD \& Martin GN 1985 The release of the endothelium derived relaxing factor from isolated human arteries. Journal of Hypertension 3 97-99.

Vega M, Johnson MC \& Diaz HA 1998 Regulation of human luteal steroidogenesis in vitro by nitric oxide. Endocrine 8 185-191.

Vega M, Urrutia L, Iñiguez G, Gabier F, Devoto L \& Johnson MC 2000 Nitric oxide induces apoptosis in the human corpus luteum in vitro. Molecular Human Reproduction 6 681-687.

Walles B, Groschel-Stewart U, Owman CH, Sjoberg NO \& Unsicker K 1978 Fluorescence histochemical demostration of a relationship between adrenergic nerves and cells containing actin and myosin in the rat ovary with special reference to the follicle wall. Journal of Reproduction and Fertility 52 174-178.

Zhu C, Palmada MN, Aguado LI \& Cavicchia JC 2002 Administration of acethylcholine to the spermatic nerve plexus inhibits testosterone secretion in and in vitro isolated rat testis-nerves plexus system. International Journal of Andrology 25 134-138.

\section{Received in final form 16 September 2006 Accepted 20 September 2006 Made available online as an Accepted Preprint 3 October 2006}

